\title{
Mitochondrial Biology and Parkinson's Disease
}

\author{
Celine Perier ${ }^{1}$ and Miquel Vila ${ }^{1,2,3}$ \\ ${ }^{1}$ Vall d'Hebron Research Institute-CIBERNED, Barcelona 08035, Spain \\ ${ }^{2}$ Catalan Institution for Research and Advanced Studies (ICREA), Barcelona 08010, Spain \\ ${ }^{3}$ Department of Biochemistry and Molecular Biology, Autonomous University of Barcelona, \\ 08193 Bellaterra, Barcelona, Spain \\ Correspondence: mvila@ir.vhebron.net
}

\begin{abstract}
Mitochondria are highly dynamic organelles with complex structural features which play several important cellular functions, such as the production of energy by oxidative phosphorylation, the regulation of calcium homeostasis, or the control of programmed cell death (PCD). Given its essential role in neuronal viability, alterations in mitochondrial biology can lead to neuron dysfunction and cell death. Defects in mitochondrial respiration have long been implicated in the etiology and pathogenesis of Parkinson's disease (PD). However, the role of mitochondria in PD extends well beyond defective respiration and also involves perturbations in mitochondrial dynamics, leading to alterations in mitochondrial morphology, intracellular trafficking, or quality control. Whether a primary or secondary event, mitochondrial dysfunction holds promise as a potential therapeutic target to halt the progression of dopaminergic neurodegeneration in PD.
\end{abstract}

M itochondria are intracellular membraneenclosed organelles found by the hundreds in most eukaryotic cells, in which they perform a number of crucial functions such as pyruvate oxidation, the Krebs cycle, the metabolism of amino acids, fatty acids, steroids, and, most importantly, the generation of energy as adenosine triphosphate (ATP). The latter function is exerted by means of the mitochondrial electron-transport chain and the oxidative-phosphorylation system (Fig. 1). From an evolutionary point of view, mitochondria are believed to originate from a symbiotic relationship established more than a billion years ago between primordial eukaryotic cells lacking the ability to use oxygen metabolically and primitive aerobic bacteria capable of oxidative phosphorylation. Through this symbiotic relationship, which became permanent, bacteria evolved into mitochondria and the host cell acquired the ability to metabolically use oxygen, a much more efficient way to produce energy than anaerobic glycolysis (DiMauro and Schon 2003).

Structurally, mitochondria contain four compartments: the outer mitochondrial membrane (OMM), the inner mitochondrial membrane (IMM), the intermembrane space (IMS), and the matrix (i.e., the region inside the inner membrane) (Fig. 1). The IMM, in which the electron transport chain (ETC) is located, is highly folded and protrudes into the matrix

Editor: Serge Przedborsk

Additional Perspectives on Parkinson's Disease available at www.perspectivesinmedicine.org

Copyright (C) 2012 Cold Spring Harbor Laboratory Press; all rights reserved; doi: 10.1101/cshperspect.a009332

Cite this article as Cold Spring Harb Perspect Med 2012;4:a009332 


\section{Perier and M. Vila}

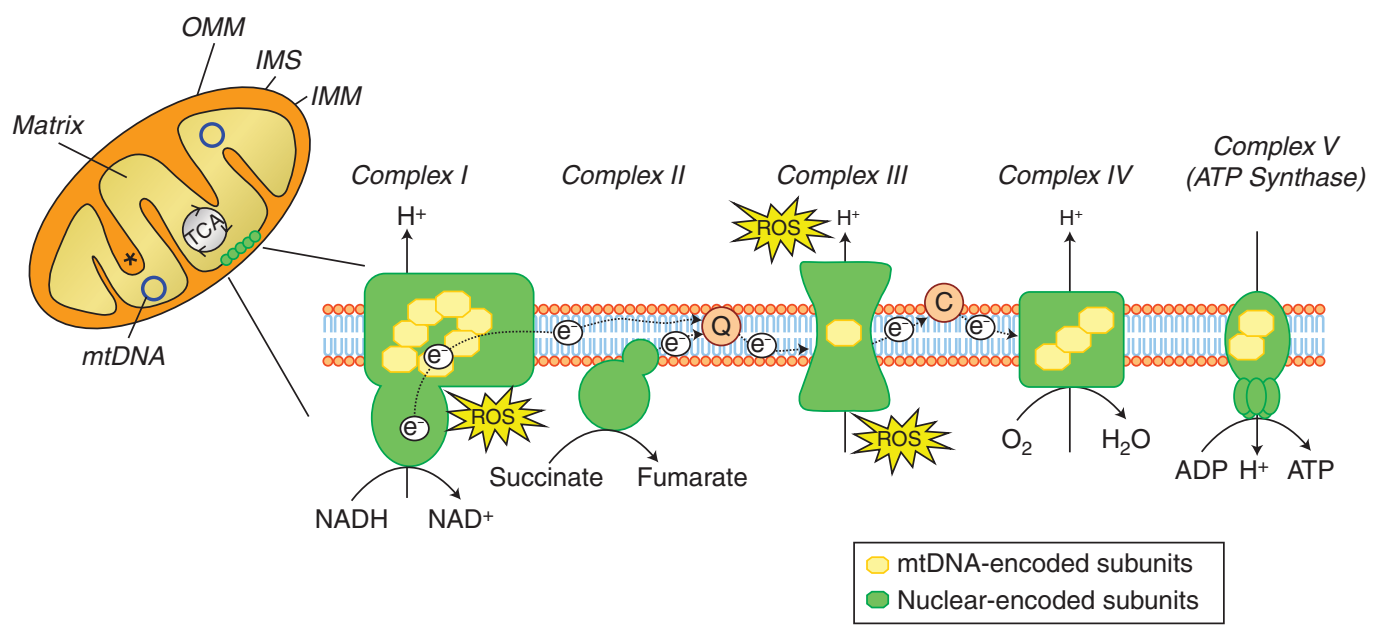

Figure 1. Schematic representation of mitochondrial compartmentalization. Mitochondria are divided in four compartments: the outer mitochondrial membrane (OMM), the intermembrane space (IMS), the inner mitochondrial membrane (IMM), and the matrix. The respiratory chain is localized at the IMM whereas the mitochondrial DNA (mtDNA) is located in the matrix. The citric acid cycle (or Krebs cycle or TCA cycle) takes place within the mitochondrial matrix. Asterisk indicates mitochondrial cristae. The respiratory chain, also known as the electron transport chain (ETC) or oxidative phosphorylation system (OXPHOS), is composed of approximately 100 proteins, 13 of which are encoded by the mtDNA. The remaining components are encoded by the nuclear DNA and imported into the mitochondria. It consists of five protein complexes; complex I (NADH dehydrogenase) and complex II (succinate dehydrogenase) receive electrons $(e-)$ from intermediary metabolism, which are then transferred to coenzyme $\mathrm{Q}$ and subsequently delivered to complex III (cytochrome $c$ reductase). The electron shuttling protein cytochrome $c$ then transfers the electrons to complex IV (cytochrome $c$ oxidase), which constitutes the final step in the ETC in which molecular oxygen is reduced to water. The electron transport is coupled to proton $\left(\mathrm{H}^{+}\right)$pumping across the IMM by complexes I, III, and IV. The resulting proton gradient drives ATP synthesis through complex V (ATP synthase). Reactive oxygen species (ROS), in the form of superoxide $\left(\mathrm{O}_{2}\right)$, can be generated by the exit of electrons at the level of complex I and III. C, cytochrome $c$; Q, coenzyme Q. (Images based on Larsson 2010.)

by invaginations called mitochondria cristae, which greatly increase the surface area of the IMM and thus the efficiency of the ETC. Mitochondria are the only organelles of the cell besides the nucleus that contain their own DNA (i.e., mitochondrial DNA, mtDNA), and their own machinery for synthesizing RNA and proteins. Each mitochondrion contains several copies of the small circular mitochondrial genome in its matrix, which encodes for 13 mitochondrial proteins that are all components of the oxidative phosphorylation system. The majority of proteins required to build and maintain functional mitochondria are therefore encoded by nuclear DNA, synthesized in the cytosol, and imported into mitochondria, where they are targeted to one of the four mitochondrial compartments.

In addition to their function in supplying cellular energy, mitochondria play a vital role in calcium homeostasis and contain several molecules involved in PCD. Furthermore, mitochondria are dynamic organelles which actively divide, fuse with one another, and undergo regulated turnover, all of which is important for the maintenance of mitochondrial function and quality control. In neurons, mitochondria are actively transported throughout axons and dendrites to facilitate their recruitment to critical subcellular compartments distant from the cell body. Alterations in any of these mitochondrial features can potentially cause disease 
and have been linked to the pathogenesis of Parkinson's disease (PD).

\section{THE MITOCHONDRIAL OXIDATIVE PHOSPHORYLATION SYSTEM}

Mitochondria are usually considered the "powerhouses of the cell" because of the production of ATP, via the combined efforts of the tricarboxylic acid cycle and the respiratory chain/oxidative phosphorylation system. The respiratory chain, located in the IMM, consists of five multimeric protein complexes: reduced nicotinamide adenine dinucleotide (NADH) dehydrogenase-ubiquinone oxidoreductase (complex I, approximately 46 subunits), succinate dehydrogenase-ubiquinone oxidoreductase (complex II, four subunits), ubiquinone-cytochrome $c$ oxidoreductase (complex III, 11 subunits), cytochrome $c$ oxidase (complex IV, 13 subunits), and ATP synthase (complex V, approximately 16 subunits) (Fig. 1). The respiratory chain also requires two small electron carriers, ubiquinone/coenzyme Q and cytochrome $c$. ATP synthesis involves two coordinated processes: electrons derived from energy substrates (such as NADH and FADH2) are transported through the different mitochondrial complexes to molecular oxygen, thereby producing water; at the same time, protons are pumped across the mitochondrial inner membrane (i.e., from the matrix to the IMS) by complexes I, III, and IV, generating an electrochemical gradient (termed mitochondrial membrane potential, $\Delta \psi)$ ). ATP is produced by the influx of these protons back into the mitochondrial matrix through complex $\mathrm{V}$ (ATP synthase). ATP is the main form of energy used by the cell and, once produced in the mitochondrion, it is exported to the cytosol by the adenine nucleotide translocator (ANT) in exchange for cytosolic ADP.

Defective mitochondrial respiration, in particular at the level of complex I, has long been associated with the pathogenesis of PD. Evidence of this involvement first emerged following the observation that accidental exposure of drug abusers to 1-methyl-4-phenyl-1,2,3,4-tetrahydropyridine (MPTP), an inhibitor of mitochondrial complex I, resulted in an acute and irreversible parkinsonian syndrome almost indistinguishable from PD (Langston et al. 1983). It was subsequently shown that MPTP selectively kills dopaminergic neurons of the substantia nigra pars compacta $(\mathrm{SNpc})$, the type of cells that preferentially degenerate in $\mathrm{PD}$, when injected into nonhuman primates and mice (Dauer and Przedborski 2003). Similarly, chronic infusion of the potent complex I inhibitor rotenone to rats has been reported to produce nigrostriatal dopaminergic neurodegeneration (Betarbet et al. 2000). A link between complex I dysfunction and PD was further established when several groups reported reduced complex I activity in the brain, platelets, and skeletal muscle of patients with sporadic PD (Parker et al. 1989; Schapira et al. 1990). In addition, cell lines engineered to contain mitochondria derived from platelets of PD patients (cybrids) were also shown to exhibit reduced complex I activity (Swerdlow et al. 1996). Supporting an instrumental role for complex I dysfunction in PD-related dopaminergic neurodegeneration, the feeding of the mitochondrial ETC directly at complex II by means of the ketone body $D-\beta$-hydroxybutyrate was shown to bypass complex I blockade, enhance oxidative phosphorylation, and attenuate dopaminergic neurodegeneration in MPTP-intoxicated mice (Tieu et al 2003). Also, virally mediated expression of yeast's single-unit NADH-quinone oxidoreductase, which is insensitive to complex I inhibitors, into the substantia nigra of rats has been shown to protect against rotenone-induced dopaminergic nigrostriatal impairment (Marella et al. 2008). Finally, methylene blue, an alternative electron carrier able to deliver electrons directly from NADH to cytochrome $c$, thus bypassing complex I blockade, attenuates mitochondrial dysfunction, behavioral alterations, and dopaminergic neurodegeneration in rotenone-intoxicated rats (Wen et al. 2011). Reinforcing a potential role for complex I defects in PD, most of the pesticides that have been epidemiologically linked to an increased risk of PD cause complex I dysfunction (Sherer et al. 2002; Schuh et al. 2005, 2009; Richardson et al. 2009). 


\section{Consequences of Complex I Blockade}

One of the expected consequences of impaired mitochondrial respiration is a reduction in ATP production and subsequent bioenergetic failure. Supporting this view, $\mathrm{MPP}^{+}$(MPTP's active metabolite) causes a rapid and profound depletion of cellular ATP levels in isolated hepatocytes (Di Monte et al. 1986), in brain synaptosomal preparations (Scotcher et al. 1990) and in whole mouse brain tissues (Chan et al. 1991). In mice, however, MPTP causes only a mild ( $\sim 20 \%)$ and transient reduction in striatal and midbrain ATP levels (Chan et al. 1991). It appears that complex I activity should be reduced by more than $50 \%$ to cause significant ATP depletion in nonsynaptic brain mitochondria (Davey and Clark 1996). Because complex I activity is only reduced by $25-30 \%$ in PD patients (Parker et al. 1989; Schapira et al. 1990), this argues against a major role for ATP depletion in PD-related dopaminergic neurodegeneration.

Another consequence of impaired mitochondrial respiration is an increased production of reactive oxygen species (ROS). In a normal situation, small amounts of molecular oxygen in the mitochondria, rather than being converted to water, are reduced to ROS such as superoxide radicals (Zhou et al. 2008). However, thanks to the arsenal of antioxidants inside the mitochondria, including the mitochondrial isoform of the ROS-scavenging enzyme superoxide dismutase (SOD2), the basal levels of ROS byproducts of mitochondrial respiration are minimal (Zhou et al. 2008). Following complex I blockade, however, the amount of ROS generated by the ETC increases dramatically, likely because of a higher rate of molecular oxygen reduction into superoxide radical in response to the hampered terminal step of electron transfer from the highest potential iron-sulfur cluster of complex I to ubiquinone (Ramsay et al. 1987). In agreement with this, $\mathrm{MPP}^{+}$and rotenone increase ROS production in isolated brain mitochondria in proportion to the degree of complex I inhibition (Perier et al 2005). Increased ROS can oxidatively damage virtually all biological macromolecules, including proteins, lipids, and DNA. For instance, complex I inhibition results in the inactivation of the mitochondrial enzyme aconitase, which is essential to maintain normal metabolic function, by oxidation of the iron-sulfur clusters contained in this enzyme (Liang and Patel 2004). Also, oxidative damage to catalytic subunits of complex I, which correlates with a misassembly and dysfunction of this complex, has been observed in frontal cortex postmortem samples from PD patients (Keeney et al. 2006). Furthermore, MPTP intoxication to mice leads to the peroxidation of the IMM phospholipid cardiolipin, thereby disrupting the normal binding of cytochrome $c$ to the mitochondrial inner membrane and thus facilitating the proapoptotic release of cytochrome $c$ to the cytosol (Perier et al. 2005). Mitochondria-derived ROS have also been shown to damage lysosomal membranes in MPTP-intoxicated mice, leading to an impairment of lysosomal function and defective autophagic degradation in these animals (Dehay et al. 2010). In addition to proteins and lipids, MPTP-intoxicated mice also exhibit oxidative damage to nuclear and mitochondrial DNA (Hoang et al. 2009). Relevant to PD, oxidative damage to proteins, lipids, and DNA have been observed in postmortem brain samples from PD patients (Dauer and Przedborski 2003). In addition, PD-linked protein DJ-1, mutations of which cause an autosomal recessive form of PD (Bonifati et al. 2003), has been identified as a mitochondrial peroxiredoxin-like peroxidase, able to scavenge mitochondrial ROS; its deficiency in mutant mice results in increased mitochondrial ROS production (Andres-Mateos et al. 2007). Supporting a pathogenic role for mitochondria-derived ROS in the context of $\mathrm{PD}$, transgenic mice overexpressing human catalase (an antioxidant enzyme normally localized in the peroxisome) specifically targeted to the mitochondria exhibit an attenuation of MPTP-induced mitochondrial ROS and reduced dopaminergic cell death (Perier et al. 2010). It is important to note, however, that increased ROS levels in the context of PD may also emanate from sources other than mitochondria, including neighboring glial cells (Zhou et al. 2008). 


\section{MITOCHONDRIAL DNA}

The human mitochondrial genome (mtDNA) consists of a $16.6 \mathrm{~kb}$ multicopy, double-stranded, circular molecule containing 37 genes of which 13 encode subunits of the respiratory chain and 24 are required for mtDNA translation within the organelle (two ribosomal RNAs and 22 transfer RNAs) (Fig. 2). Mitochondrial genetics differs from mendelian genetics in several aspects (DiMauro and Schon 2003). For instance, mtDNA is transmitted through the maternal line, which implies that a mother carrying an mtDNA mutation will pass it on to all her children, but only her daughters will transmit it to their progeny. Also, each mitochondrion contains several copies of mtDNA, resulting in thousands of mtDNA molecules per cell. In normal subjects, all mtDNAs are identical (homoplasmy). In contrast, pathogenic mtDNA mutations are usually present in some, but not all, of these genomes. In the latter situation, cells and tissues, and even individual mitochondria, can harbor both normal and mutant mtDNA (heteroplasmy). In the case of heteroplasmy, a minimal number of mutant mtDNAs is required to cause mitochondrial dysfunction and clinical signs, a phenomenon known as the threshold effect (Fig. 2). The threshold for disease is lower in tissues that are highly dependent on oxidative metabolism, such as brain, heart, or skeletal muscle, rendering these tissues especially vulnerable to the effects of pathogenic mtDNA mutations.

Transfer of mtDNA from platelets of PD patients into cells depleted of their own mtDNA recapitulates complex I deficiency and other pathogenic features of PD (Swerdlow et al. 1996; Gu et al. 1998; Trimmer et al. 2004). This observation indicates that PD-derived $\mathrm{mtDNA}$ encodes pathogenic information, raising the possibility that mitochondrial alterations in
A

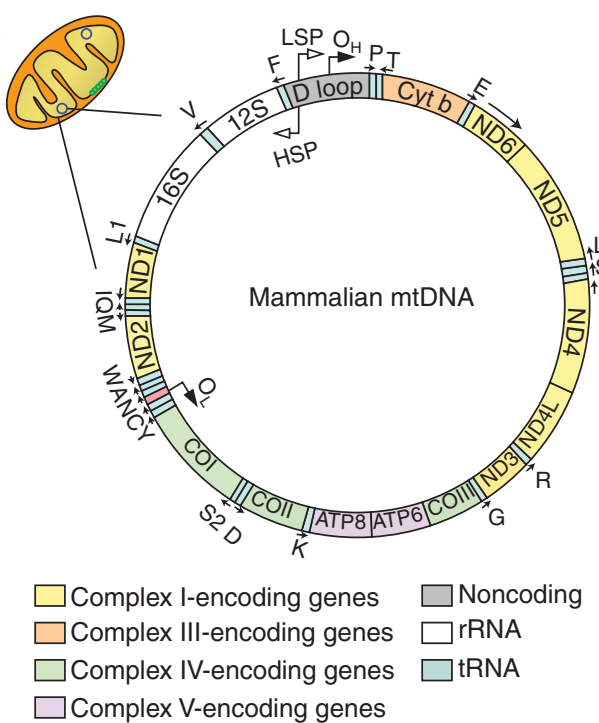

B

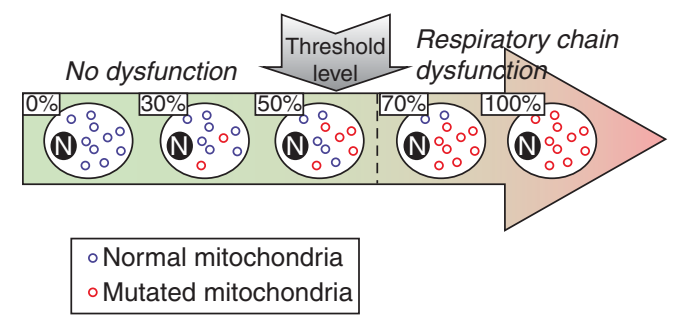

Figure 2. Mitochondrial DNA (mtDNA). (A) Mammalian mtDNA is a double-stranded circular molecule containing 37 genes: two ribosomal RNAs (12S and 16S rRNA), 22 transfer RNAs (tRNAs: F, V, L1, I, M, W, D, K, G, R, H, S1, L2, T, P, E, S2, Y, C, N, A, Q), and 13 encoding subunits of the respiratory chain, including seven subunits of complex I (ND1, 2, 3, 4, 4L, 5, and 6), one subunit of complex III (cytochrome $b$ ), three subunits of cytochrome $c$ oxidase (COX I, II, and III) and two subunits of ATP synthase (ATP6 and ATP8). (B) In a normal situation, all mtDNAs within a cell are identical (homoplasmy). In a pathological situation linked to pathogenic mtDNA mutations, cells can harbor both normal and mutant mtDNA (heteroplasmy). In the latter case, a minimal number of mutated mtDNAs is required to cause mitochondrial dysfunction and clinical signs (threshold effect). (Images based on Larsson 2010.) 
PD may be inherited from the mitochondrial genome or related to somatic mtDNA alterations acquired during aging. Whereas maternally inherited parkinsonism associated with mtDNA mutations is rare (Thyagarajan et al. 2000), several studies suggest that acquired mtDNA abnormalities may contribute to PD pathogenesis. In humans, mutations in mtDNA polymerase $\gamma$ (POLG), the enzyme responsible for the synthesis and proofreading of mtDNA, are associated with levodopa-responsive parkinsonism, usually as part of a more complex syndrome (Luoma et al. 2004; Davidzon et al. 2006). In these families, affected individuals exhibit reduced striatal dopamine uptake on positron emission tomography (PET) analysis and severe loss of pigmented neurons in the substantia nigra at postmortem examination, although no Lewy bodies are observed (Luoma et al. 2004). In all these patients, POLG mutations result in the accumulation of multiple mtDNA deletions in muscle (Luoma et al. 2004; Davidzon et al. 2006). Remarkably, mtDNA deletions have been observed in individual dopaminergic neurons microdissected from the substantia nigra of postmortem human brains from aged individuals and idiopathic PD patients (Bender et al. 2006; Kraytsberg et al. 2006). Different SNpc dopaminergic neurons from the same individual contained unique mtDNA deletions, indicating that these deletions were acquired throughout life (Bender et al. 2006). Furthermore, high levels of mtDNA deletions in these neurons were associated with decreased histochemical activity of mitochondrial complex IV, suggesting that the accumulation of mtDNA deletions over a certain threshold in SNpc dopaminergic neurons may cause mitochondrial functional defects (Bender et al. 2006; Kraytsberg et al. 2006). Mitochondrial ROS may be responsible for the high level of somatic mtDNA alterations occurring in SNpc dopaminergic neurons. Because of its proximity to the site of ROS production within the mitochondria, mtDNA can be oxidatively damaged during aging or following increased mitochondrial ROS production linked to complex I defects. Consistent with this view, mutant mice overexpressing the anti- oxidant enzyme catalase specifically in the mitochondria exhibit reduced accumulation of mtDNA mutations during aging (Vermulst et al. 2007). In addition, increased ROS production following MPTP intoxication to mice results in oxidative damage to striatal mtDNA (Hoang et al. 2009). Although it remains to be determined whether mtDNA alterations represent a primary or secondary event in $\mathrm{PD}$, mice with a conditional disruption in dopaminergic neurons of mitochondrial transcription factor A (TFAM), which regulates mtDNA transcription, exhibit reduced mtDNA expression, respiratory chain defects, and slowly progressive levodopa-responsive motor deficits associated with progressive nigrostriatal denervation (Ekstrand et al. 2007), suggesting that impaired mtDNA expression may primarily contribute to the pathogenesis of PD.

\section{MITOCHONDRIAL DYNAMICS}

Mitochondria are not autonomous, rigidly structured organelles, but highly dynamic structures, which continually fuse and divide, move along the cell, and undergo regulated turnover, all of which ensure an adequate mitochondrial function at the appropriate time and subcellular location in order to adapt to changes in cellular requirements. Stressing the importance of these processes, defects in mitochondrial dynamics lead to neurological diseases and may contribute to PD.

\section{Mitochondrial Fusion and Fission}

The hundreds of mitochondria within a cell undergo continual cycles of fusion (the combination of two mitochondria into a single organelle) and fission (the separation of long, tubular mitochondria into two or more smaller parts), resulting in a wide range of mitochondrial morphologies (Fig. 3A; Detmer and Chan 2007; Knott et al. 2008). The adequate balance between fusion and fission is crucial for the maintenance of mitochondrial function. For instance, mitochondrial fusion is required for the proper respiratory activity of the mitochondria and has been associated with 
cell survival (Chen et al. 2007). In addition, the functionality of damaged mitochondria can be restored by exchanging mitochondrial genomes and gene products by fusion with neighboring, intact mitochondria, thereby attenuating the potential deleterious effects of misfolded proteins or mutated mtDNAs (Detmer and Chan 2007; Schon and Przedborski 2011). The proper localization of mitochondria to nerve terminals also depends on the correct balance between mitochondrial fusion and fission, as fragmentation of the mitochondrial network by fission appears to facilitate the recruitment of mitochondria to nerve terminals (Brown et al. 2006).

At the molecular level, mitochondrial fusion and fission are regulated by a series of GTPases: mitofusins 1 and 2 (Mfn1, Mfn2) for outer membrane fusion, optic atrophy 1 (OPA1) for inner membrane fusion, and dynaminrelated protein 1 (Drp1) for mitochondrial fis- sion (Fig. 3A; Chen and Chan 2009). Alterations in this molecular machinery lead to defects in mitochondrial function and can cause cell death and disease. For instance, mutations in Mfn2 and OPA1 result in defective mitochondrial fusion and cause inherited neurodegenerative disorders such as CharcotMarie-Tooth disease type 2A or dominant optic atrophy, respectively (Delettre et al. 2000; Zuchner et al. 2004). Also, defective mitochondrial fission linked to mutations in Drp1 results in neurons with elongated mitochondria largely absent from synapses and unable to maintain normal neurotransmission during intense stimulation (Verstreken et al. 2005). On the other hand, excessive Drp1-mediated mitochondrial fission is associated with apoptosis, probably resulting from the enhanced release of mitochondrial pro-apoptotic molecules, such as cytochrome $c$, to the cytosol (Frank et al. 2001).
A

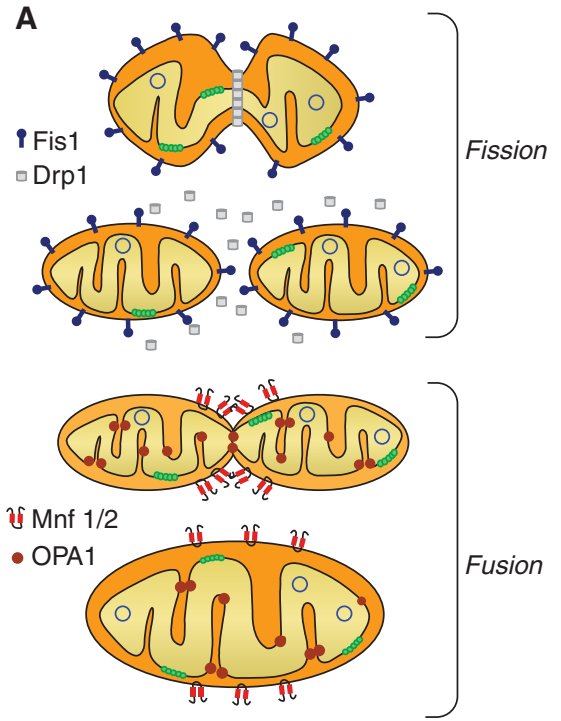

B

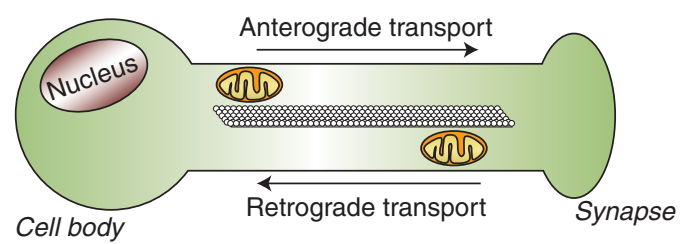

C

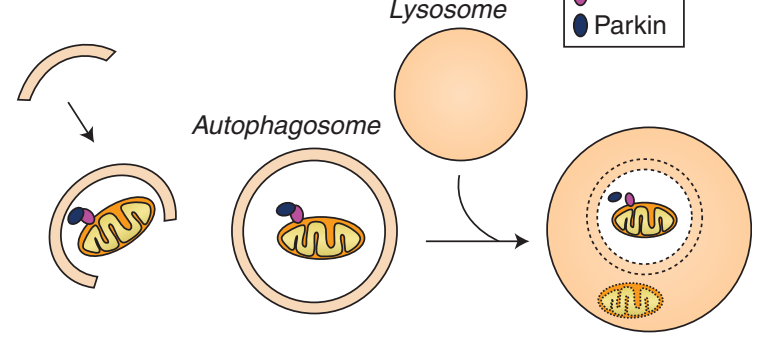

Figure 3. Mitochondrial dynamics. (A) Mitochondrial fusion and fission control mitochondrial number and size. Fission is mediated by dynamin-related protein 1 (Drp1) and mitochondrial fission-1 protein (Fis1). Mitofusins (Mnf) 1 and 2 are involved in the fusion of the OMM, whereas protein optic atrophy type 1 (OPA1) regulates the fusion of the IMM. $(B)$ In neurons, mitochondria are recruited to subcellular compartments distant from the cell body, such axons and dendrites, by active transport along microtubules and actin filaments. Distinct molecular motors transport the mitochondria in anterograde or retrograde directions. $(C)$ Selective autophagic degradation of mitochondria (i.e., mitophagy) involves the recruitment of damaged mitochondria into a preautophagosome structure via a PINK1/Parkin-dependent process. Targeted mitochondria are then sequestered into double-membrane-bounded autophagosomes and subsequently delivered to lysosomes for degradation. 
In the context of $\mathrm{PD}$, cell death induced by parkinsonian neurotoxins 6-OHDA, rotenone, and $\mathrm{MPP}^{+}$in cultured neurons is associated with mitochondrial fragmentation (Barsoum et al. 2006; Meuer et al. 2007; Gomez-Lazaro et al. 2008). Supporting a pathogenic role for the latter, genetic inhibition of pro-fission Drp1 or overexpression of pro-fusion Mfn1 prevent cell death induced by these neurotoxins (Barsoum et al. 2006; Meuer et al. 2007; GomezLazaro et al. 2008). Furthermore, pathogenic mutations in Parkin (an E3 ubiquitin ligase) and PINK1 (PTEN-induced putative kinase-1, a mitochondrially targeted kinase), which cause autosomal recessive forms of PD (Vila and Przedborski 2004), are associated with an increase in dysfunctional, fragmented mitochondria that can be rescued by pharmacological or genetic inactivation of Drp1 (Lutz et al. 2009; Cui et al. 2010). Also, DJ-1 deficiency in cultured cells results in ROS-dependent mitochondrial fragmentation, which can be prevented by PINK1 and Parkin overexpression (Irrcher et al. 2010). In addition, $\alpha$-synuclein binding to mitochondrial membranes causes a Drp1-independent mitochondrial fragmentation that can be prevented by PINK1, Parkin, or DJ-1 overexpression (Kamp et al. 2010; Nakamura et al. 2011). However, alterations in mitochondrial fusion/ fission balance have not yet been directly shown in PD.

\section{Mitochondrial Motility and Regional Distribution}

In neurons, mitochondria are actively recruited to subcellular sites distant from the cell body, such as the axonal and dendritic processes, reflecting the high levels of ATP required for synaptic transmission and the need to regulate $\mathrm{Ca}^{2+}$ homeostasis during intense synaptic activity (Keating 2008). Neuronal populations selectively vulnerable to PD, such as SNpc dopaminergic neurons, are characterized by having long, thin axons with little or no myelination (Braak et al.2004). This feature may render these neurons more susceptible to potential alterations in mitochondrial motility, because of the high metabolic demands for the transmission of impulses along poorly myelinated axons and the long distances that mitochondria have to travel between cell bodies and axon terminals in these neurons (Vives-Bauza et al. 2010a). Indeed, compared to nondopaminergic neurons, SNpc dopaminergic neurons exhibit: (i) three times slower mitochondrial axonal transport (Kim-Han et al. 2011), (ii) a reduced number of mitochondria in cell body and dendrites (Liang et al. 2007), and (iii) smaller mitochondrial size (Kim-Han et al. 2011).

Mitochondria move along cytoskeletal tracks, such as microtubules and actin filaments, using distinct molecular motors (Fig. 3B). Short-range mitochondrial transport along actin filaments requires myosin motors whereas long-range transport on microtubules requires dynein/dynactin for retrograde transport and kinesins for anterograde transport (Hollenbeck 1996; Jung et al. 2004; Schon and Przedborski 2011). Relevant to $\mathrm{PD}, \mathrm{MPP}^{+}$was shown to impair kinesin-mediated anterograde fast axonal transport in isolated squid axoplasm (Morfini et al. 2007), and overall axonal motility of mitochondria, but not of other moving particles, in murine mesencephalic cultures (Kim-Han et al. 2011). In addition, proteins linked to familial forms of PD, such as PINK1, Parkin, $\alpha$-synuclein, or LRRK2, have been reported to interact with, and potentially impair, microtubule-mediated trafficking (Schon and Przedborski 2011). However, direct evidence of mitochondrial trafficking alterations in PD patients is still lacking, probably because of the technical difficulties in analyzing mitochondrial transport in human-derived material.

To reach nerve terminals, tubular mitochondria is disgregated by fission into smaller, more motile fragments (Brown et al. 2006). Accordingly, synaptic mitochondria appear mostly punctate, rather than tubular (Brown et al. 2006). However, punctate synaptic mitochondria have limited ability to buffer $\mathrm{Ca}^{2+}$, compared to elongated nonsynaptic mitochondria, and appear more susceptible to $\mathrm{Ca}^{2+}$ overload (Brown et al. 2006). Synaptic mitochondria are also more sensitive to complex I inhibition than their nonsynaptic counterparts. In nonsynaptic mitochondria, complex I can be inhibited 
by $70 \%$ before major changes in mitochondrial respiration and ATP production are detected (Davey and Clark 1996). In contrast, in synaptic mitochondria, this threshold is lowered to $25 \%$, which is within the range of complex I impairment found in PD patients (Davey et al. 1998). Synaptic mitochondria also exhibit lower levels of cardiolipin than their nonsynaptic counterparts (Kiebish et al. 2008), which may lower the threshold for the pro-apoptotic release of cytochrome $c$. These observations may explain, at least in part, the apparent increased susceptibility of striatal dopaminergic terminals, compared to dopaminergic nigral cell bodies, to the degenerative process in PD (Cheng et al. 2010).

\section{Mitochondrial Turnover}

Selective autophagic degradation of mitochondria, termed mitophagy, is necessary for the steady-state turnover of mitochondria, the adjustment of mitochondrion numbers to changing metabolic demands, or the removal of damaged mitochondria (Kim et al. 2007; Youle and Narendra 2011). Using the core autophagic machinery, mitophagy involves the sequestration of targeted mitochondria into double-membrane-bounded structures known as autophagosomes (Fig. 3C). Subsequently, autophagosomes fuse with lysosomes (i.e., cytoplasmic membrane-enclosed organelles that contain a wide variety of hydrolytic enzymes) in which sequestered mitochondria are degraded. Functional mitochondrial alterations, such as loss of $\Delta \psi$ or permeabilization of the OMM, trigger mitophagy, probably in an attempt to limit potential deleterious effects associated with damaged mitochondria such as excessive ROS production or enhanced release of mitochondrial pro-apoptotic factors (Tait and Green 2010).

In $\mathrm{PD}$, overall autophagic degradation, including mitophagy, seems to be impaired. Indeed, in experimental PD models and postmortem PD brain samples, abnormal mitochondria readily accumulate in the cytosol of affected neurons (Dehay et al. 2010; Vila et al. 2011), indicating that it cannot be efficiently degraded through mitophagy. Accumulation of dysfunctional mitochondria may contribute to dopaminergic cell death by an increased production of ROS and an enhanced release of mitochondrial apoptogenic factors (Vila et al. 2001; Vila and Przedborski 2003; Perier et al. 2005, 2007). Defective autophagy in PD originates, at least in part (Martinez-Vicente et al. 2008), from a pathogenic reduction in the amount of functional lysosomes (Chu et al. 2009; Dehay et al. 2010). Lysosomal breakdown in PD appears secondary to the abnormal permeabilization of lysosomal membranes by mitochondrially driven oxidative attack (Dehay et al. 2010), leading to a vicious cycle in which increased ROS production from dysfunctional mitochondria contributes to defective autophagy by oxidatively damaging lysosomal membranes, thereby resulting in a further accumulation of altered mitochondria which cannot be degraded through mitophagy. Supporting a pathogenic role for decreased autophagy/ mitophagy in $\mathrm{PD}$, pharmacological restoration of lysosomal-mediated degradation by rapamycin is able to reduce the cytosolic accumulation of undegraded autophagosomes (which contain abnormal mitochondria) and attenuate dopaminergic neurodegeneration in MPTPintoxicated mice (Dehay et al. 2010; Bové et al. 2011). Besides a general impairment of autophagic degradation, specific defects in mitophagy may also occur in PD. For instance, PD-linked mutations in PINK1 and Parkin have been shown to disrupt the coordinated normal regulatory role of these molecules at promoting autophagic degradation of dysfunctional mitochondria, thereby leading to defective mitophagy (Geisler et al. 2010; Narendra et al. 2010; Vives-Bauza et al. 2010b).

\section{MITOCHONDRIA AND CALCIUM HOMEOSTASIS}

Intracellular calcium $\left(\mathrm{Ca}^{2+}\right)$ regulates an array of cellular processes and is important for signal transduction. In neurons, $\mathrm{Ca}^{2+}$ acts as the main second messenger to transmit depolarization status and synaptic activity to the biochemical machinery of neurons (Gleichmann and Mattson 2011). The concentration of cytosolic free 
$\mathrm{Ca}^{2+}$ in resting neurons $(\sim 100 \mathrm{nM})$ is $10,000-$ fold lower than the concentration of $\mathrm{Ca}^{2+}$ in the extracellular space $(\sim 1.2 \mathrm{~mm})$ (Gleichmann and Mattson 2011). This concentration gradient leads to a significant increase in cytosolic $\mathrm{Ca}^{2+}$ after depolarization, rendering $\mathrm{Ca}^{2+}$ regulation a critical process in neurons. To maintain $\mathrm{Ca}^{2+}$ homeostasis, $\mathrm{Ca}^{2+}$ entering neurons is rapidly sequestered in intracellular organelles, such as the mitochondria and the endoplasmic reticulum (ER), or pumped back across the plasma membrane concentration gradient, all of which require high levels of energy in the form of ATP. The ability to accumulate, retain, and release $\mathrm{Ca}^{2+}$ is a fundamental property of mitochondria. Accumulation of $\mathrm{Ca}^{2+}$ within the mitochondrial matrix depends on both $\mathrm{Ca}^{2+}$ uptake into the mitochondria through an electrogenic uniporter, as well as extrusion of $\mathrm{Ca}^{2+}$ from the mitochondria through $\mathrm{Na}^{+} /$ $\mathrm{Ca}^{2+}$ and $\mathrm{H}^{+} / \mathrm{Ca}^{2+}$ antiporters (Szabadkai et al. 2006; De Stefani et al. 2011). The most significant intracellular storage site of $\mathrm{Ca}^{2+}$, however, is the ER, and there is a significant interplay between mitochondria and ER in relation to $\mathrm{Ca}^{2+}$. These two organelles are linked, both biochemically and physically (Csordas et al. 2006; de Brito and Scorrano 2008), which facilitates efficient $\mathrm{Ca}^{2+}$ transmission from the ER to the mitochondria. The accumulation of $\mathrm{Ca}^{2+}$ in the mitochondria leads to the activation of oxidative phosphorylation and subsequent increase in ATP production (Gleichmann and Mattson 2011), thus helping to meet the metabolic demands associated with neuronal electrical activity.

During normal synaptic activity, intracellular $\mathrm{Ca}^{2+}$ concentrations increase only transiently (seconds to a few minutes) and have no adverse effects on neurons. However, unlike most neurons in the brain, adult SNpc dopaminergic neurons are autonomously active, generating action potentials in a clock-like manner in the absence of synaptic input (Chan et al. 2007). The pacemaking activity of these neurons is driven by voltage-dependent L-type $\mathrm{Ca}^{2+}$ channels, leading to sustained elevations in cytosolic $\mathrm{Ca}^{2+}$ concentrations in these cells (Chan et al. 2007). The large $\mathrm{Ca}^{2+}$-buffering burden created by pacemaking activity in SNpc dopaminergic neurons ultimately compromises mitochondrial function, resulting in mitochondrial oxidative stress and oscillations in mitochondrial potential, the latter being associated with compromised ATP production (Guzman et al. 2010). Supporting a pathogenic role for increased $\mathrm{Ca}^{2+}$ load linked to pacemaking activity, the L-type $\mathrm{Ca}^{2+}$ channel antagonist isradipine is able to attenuate rotenone-induced dendritic loss in adult ventral midbrain slices and to reduce $\mathrm{SNpc}$ dopaminergic neurodegeneration in MPTP-intoxicated mice (Chan et al. 2007). These observations suggest that sustained mitochondrial $\mathrm{Ca}^{2+}$ overload in adult $\mathrm{SNpc}$ dopaminergic neurons may render these cells selectively vulnerable to PD. In agreement with this, neighboring dopaminergic neurons in the ventral tegmental area (VTA), which do not rely on L-type $\mathrm{Ca}^{2+}$ channels for pacemaking, are relatively preserved in PD (Chan et al. 2010). In addition, expression of $\mathrm{Ca}^{2+}$-buffering protein calbindin in selected SNpc dopaminergic populations is negatively correlated with PD-linked cell loss (German et al. 1992; Damier et al. 1999).

Other studies further support a role for alterations in mitochondrial $\mathrm{Ca}^{2+}$ homeostasis in PD. For instance, cybrid cells containing mtDNA from PD patients exhibit lower mitochondrial $\mathrm{Ca}^{2+}$ sequestration than control cells following carbachol-stimulated $\mathrm{Ca}^{2+}$ entry (Sheehan et al. 1997). Similarly, parkinsonian neurotoxins $\mathrm{MPP}^{+}$and rotenone cause diminished mitochondrial $\mathrm{Ca}^{2+}$ uptake and increased cytosolic free $\mathrm{Ca}^{2+}$ in cultured cells (Frei and Richter 1986; Sousa et al. 2003; Wang and Xu 2005). Also, exogenously applied oligomeric, but not monomeric, $\alpha$-synuclein to cultured dopaminergic neurons was shown to increase intracellular $\mathrm{Ca}^{2+}$ levels through a pore-mediated influx of extracellular $\mathrm{Ca}^{2+}$, leading to increased mitochondrial $\mathrm{Ca}^{2+}$-buffering burden and apoptotic cell death (Danzer et al. 2007). Furthermore, PD-related protein PINK1 appears to regulate the physiological release of $\mathrm{Ca}^{2+}$ from the mitochondria via the mitochondrial $\mathrm{Na}^{+} / \mathrm{Ca}^{2+}$ exchanger (Gandhi et al. 2009). Indeed, ablation of PINK1 in dopaminergic 
neurons leads to impaired $\mathrm{Ca}^{2+}$ efflux from mitochondria, accumulation of mitochondrial $\mathrm{Ca}^{2+}$, increased production of mitochondrial ROS, decreased mitochondrial respiration, reduced $\Delta \psi$, and a lowered threshold for $\mathrm{Ca}^{2+}$ dependent opening of the mitochondrial permeability transition pore complex, overall resulting in increased apoptosis (Gandhi et al. 2009). Supporting a role for increased $\mathrm{Ca}^{2+}$ load in PD-related cell death in vivo, pharmacological or genetic inhibition of $\mathrm{Ca}^{2+}$-sensitive proteases (i.e., calpains) has been shown to attenuate dopaminergic neurodegeneration in MPTP-intoxicated mice (Crocker et al. 2003).

\section{MITOCHONDRIA AND PROGRAMMED CELL DEATH}

PCD, a physiologic process in which molecular programs intrinsic to the cell are activated to cause its own destruction, is a fundamental property of all pluricellular organisms and is crucial for their development, organ morphogenesis, tissue homeostasis, and defense against infected or damaged cells. However, excessive PCD or abnormal reactivation of PCD in adulthood can lead to neurodegeneration (Vila and Przedborski 2003). Mitochondria play a central role in the regulation of PCD, as they contain several molecules which, when abnormally released into the cytosol following mitochondrial outer membrane permeabilization (MOMP), activate caspase-dependent or caspase-independent PCD pathways (Fig. 4). MOMP represents the point-of-no-return in mitochondrial-dependent PCD and is highly regulated by a series of proteins of the $\mathrm{Bcl}-2$ family that either prevent (e.g., Bcl-2 and Bcl-xL) or promote (e.g., Bax and Bak) MOMP and subsequent cell death (Vila and Przedborski 2003). Although the exact mechanism by which pro-apoptotic proteins, such as Bax, induce MOMP is still a matter of debate, it requires the translocation and insertion of these proteins into mitochondrial membranes, whence they can elicit the release of mitochondrial apoptogenic factors, such as cytochrome $c$, by at least two distinct described mechanisms: one involving the opening of the so-called mitochondrial permeability transition pore complex, and another dependent on the formation of channels directly by these proteins into mitochondrial membranes (Galluzzi et al. 2009).

In experimental PD models, dopaminergic neurodegeneration appears to occur, at least in part, through activation of mitochondria-dependent PCD pathways (Vila and Przedborski 2003; Perier et al. 2011). In MPTP-intoxicated mice, there is a time-dependent, region-specific mitochondrial release of cytochrome $c$ followed by activation of caspase- 9 , caspase-3, and apoptotic nigral cell death (Perier et al. 2005). All these MPTP-induced molecular events, including dopaminergic neurodegeneration, are regulated by pro-apoptotic protein Bax, as they coincide with Bax mitochondrial translocation and are prevented by genetic ablation of Bax (Vila et al. 2001; Perier et al. 2005, 2007). Further supporting the involvement of mitochondria-dependent PCD in PD, dopaminergic neurodegeneration caused by MPTP in mice can also be attenuated by targeting other molecules of this pathway, such as caspase-9 or Apaf-1 (Mochizuki et al. 2001; Viswanath et al. 2001) or by overexpressing Bcl-2 (Offen et al. 1998; Yang et al. 1998). Importantly, complex I inhibition by either $\mathrm{MPP}^{+}$, rotenone, or pathogenic complex I mutations does not directly trigger mitochondrial cytochrome $c$ release but instead increases the "releasable" soluble pool of cytochrome $c$ in the mitochondrial IMS that can subsequently be released to the cytosol by activated Bax (Perier et al. 2005). This effect is mediated by peroxidation of the IMM phospholipid cardiolipin, which disrupts the normal binding of cytochrome $c$ to the mitochondrial inner membrane (Perier et al. 2005). In addition to its detachment from the mitochondrial inner membrane, cytochrome $c$ release also requires, in other cellular settings, a remodeling of mitochondrial cristae mediated by OPA1 (Scorrano et al. 2002; Frezza et al. 2006).

A role for mitochondria-dependent PCD in $\mathrm{PD}$ is further reinforced by the finding that many of the mutated nuclear genes associated with familial forms of PD either directly or indirectly affect mitochondria-dependent PCD 


\section{Perier and M. Vila}

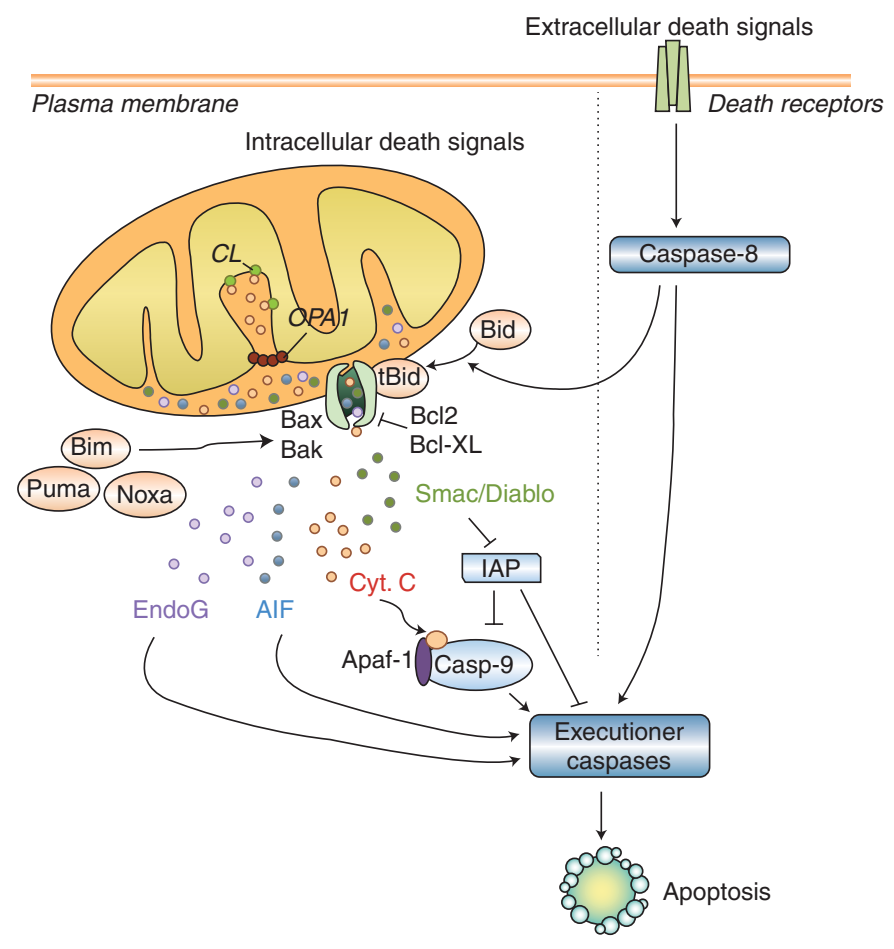

Figure 4. Mitochondrial-dependent apoptosis. Apoptosis can result from the activation of two distinct molecular cascades, known as the extrinsic (or death receptor) and the intrinsic (or mitochondrial) pathways. Both pathways, which can converge at the level of mitochondria, involve the activation of initiator caspases (caspase- 8 and -9 , respectively) that catalyze the proteolytic maturation of downstream executioner caspases, such as caspase-3, which are the final effectors of cell death. Mitochondrial outer membrane permeabilization (MOMP) represents the point-of-no-return in the mitochondrial apoptotic pathway. Following MOMP, mitochondrial apoptogenic factors such as cytochrome $c$, Smac/Diablo, endonuclease G, or apoptosis-inducing factor (AIF) are released to the cytosol. Once into the cytosol, these factors can initiate cell death in a caspase-dependent or a caspase-independent manner. Released cytochrome $c$ interacts with two other cytosolic protein factors, Apaf-1 and procaspase-9, to activate caspase-3. Smac/Diablo can interact with several inhibitors of apoptosis (IAPs), thereby relieving the inhibitory effect of IAPs on initiator (e.g., caspase-9) and effector (e.g., caspase-3) caspases. AIF and endonuclease G can translocate to the nucleus and induce caspase-independent DNA fragmentation. MOMP is highly regulated by anti-apoptotic (e.g., Bcl-2 and Bcl-xL) and pro-apoptotic (e.g., Bax and Bak) protein members of the Bcl-2 family. Structurally, all these proteins share up to four $\mathrm{Bcl}-2$-homology domains (BH1-BH4). In addition to multidomain Bcl-2 family members, there are molecules that share sequence homology only with the BH3 domain (such as Bid, Bim, Puma, and Noxa) which can induce cell death either by activating multidomain pro-apoptotic proteins or by inactivating anti-apoptotic proteins. Bid is activated following its cleavage by caspase-8, thus linking the extrinsic and intrinsic pathways at the level of the mitochondria. Whereas several components of the mitochondrial apoptotic pathway have been implicated in the pathogenesis of $\mathrm{PD}$, the participation of the extrinsic pathway in $\mathrm{PD}$ has not been consistently shown (Perier et al. 2011). AIF, apoptosis-inducing factor; Casp-9, caspase-9; CL, cardiolipin; OPA1, optic atrophy type 1; Cyt. c, cytochrome $c$; EndoG, endonuclease G; IAP, inhibitor of apoptosis; tBid, truncated Bid.

pathways (Vila et al. 2008). For instance, overexpression of $\alpha$-synuclein in vivo kills dopaminergic neurons by apoptosis through activation of caspase-9 and caspase-3 (Yamada et al. 2004). Furthermore, aggregated, but not nonaggregated, $\alpha$-synuclein induces cytochrome $c$ release in isolated rat brain mitochondria (Parihar et al. 2008). In cell lines, PD-linked mutations in LRRK2 lead to mitochondria-dependent PCD through the release of cytochrome $c$ (Iaccarino 
et al. 2007). Also, overexpression of wild-type PINK1, but not of PD-associated PINK1 mutants, is able to attenuate cytochrome $c$ release, caspase activation, and apoptosis induced by parkinsonian neurotoxins or hydrogen peroxide in cultured cells (Petit et al. 2005; Wang et al. 2007). Similarly, Parkin was shown to prevent ceramide-induced cytochrome $c$ release, caspase activation, and apoptotic cell death in vitro (Darios et al. 2003), an effect that was abolished by PD-causing Parkin mutations (Darios et al. 2003). Overall, these results suggest that activation of mitochondria-dependent PCD pathways contributes to dopaminergic neurodegeneration in PD.

\section{MITOCHONDRIA AND AGING}

Increasing age is the most consistent risk factor for PD and mitochondria have long been suspected to play an essential role in aging. Indeed, it has been postulated that mitochondrial ROS accumulation in multiple tissues over the years may result in mtDNA alterations, mitochondrial dysfunction, and cell death, leading to the decline in tissue function associated with aging (Wallace 2005). Consistent with this view, genetic ablation of the pro-apoptotic mitochondrial ROS-producing protein p66Shc extends the lifespan of mutant mice (Migliaccio et al. 1999; Pinton et al. 2007). In addition, mutant mice overexpressing the antioxidant enzyme catalase specifically in the mitochondria exhibit reduced accumulation of mtDNA mutations (Vermulst et al. 2007) and increased lifespan (Schriner et al. 2005). Conversely, mutant mice with proofreading-deficient forms of POLG accumulate high levels of mtDNA alterations in all tissues and exhibit decreased mitochondrial respiration, increased apoptosis, accelerated aging, and reduced lifespan (Trifunovic et al. 2004; Kujoth et al. 2005). Some of these molecular events may underlie the link between mitochondria, aging, and PD. For instance, as mentioned earlier in this paper, mutant mice overexpressing mitochondrial catalase not only exhibit extended lifespan but are also more resistant to MPTP-induced dopaminergic cell death (Perier et al. 2010). Also, high levels of mtDNA deletions, which are responsible for the premature aging phenotype and shortened lifespan observed in the POLG mutant mice (Vermulst et al. 2007, 2008), have also been detected in SNpc dopaminergic neurons from postmortem human brains from aged individuals and PD patients (Bender et al. 2006; Kraytsberg et al. 2006). Furthermore, mutations in POLG are associated with parkinsonism in humans (Luoma et al. 2004; Davidzon et al. 2006).

Other potential links between mitochondria, aging, and PD are provided by members of the sirtuin family of protein deacetylases, which promote longevity in several organisms. Three of the seven mammalian sirtuins (SIRT3, 4 , and 5) are targeted to mitochondria, and SIRT1 promotes mitochondrial biogenesis by deacetylating and activating PGC- $1 \alpha$ (peroxisome proliferator-activated receptor- $\gamma$ coactivator $1 \alpha$ ), a transcriptional coactivator of nuclear genes encoding mitochondrial proteins (Guarente 2008). Pharmacological activation of SIRT1 protects dopaminergic neurons from midbrain slice cultures against $\mathrm{MPP}^{+}$intoxication (Okawara et al. 2007). Downstream from SIRT1, genetic ablation of PGC- $1 \alpha$ in mutant mice increases the sensitivity of these animals to MPTP-induced dopaminergic cell death (St Pierre et al. 2006). Conversely, overexpression of PGC- $1 \alpha$ results in increased expression of nuclear-encoded subunits of the mitochondrial respiratory chain and blocks neuronal loss induced by mutant $\alpha$-synuclein, rotenone, or paraquat in cellular disease models (St Pierre et al. 2006; Zheng et al. 2010). Further linking PGC- $1 \alpha$ with PD, a newly identified partner of PD-related protein Parkin, named PARIS (Parkin-interacting substrate), was shown to be a repressor of PGC- $1 \alpha$ expression (Shin et al. 2011). Supporting a pathogenic role for PARISinduced PGC- $1 \alpha$ repression, overexpression of PARIS in the substantia nigra of mice leads to dopaminergic cell death that can be reversed by PGC-1 $\alpha$ co-expression (Shin et al. 2011). Finally, indicating a link between mitochondria quality control, aging, and PD, treatment with rapamycin, a pharmacological compound able to activate autophagy/mitophagy, has been 


\section{Perier and M. Vila}

shown to extend lifespan in several species, including aged mice (Harrison et al. 2009; Anisimov et al. 2010), and to attenuate dopaminergic neurodegeneration in MPTP-intoxicated mice (Dehay et al. 2010; Bové et al. 2011).

\section{CONCLUSIONS}

Given the essential role of mitochondria in cell viability, alterations in mitochondria biology can lead to cell dysfunction and cell death. Neurons are particularly vulnerable to mitochondrial impairment because of their dependence for energy on the mitochondrial metabolism of pyruvate produced from glucose by the glycolytic pathway or the need to recruit mitochondria to axons and dendrites. Dopaminergic SNpc neurons, in particular, are especially susceptible to mitochondrial alterations because of the increased mitochondrial $\mathrm{Ca}^{2+}$ buffering burden created by autonomous pacemaking activity in these cells and their long, poorly myelinated axons. Defects in mitochondrial respiration have indeed been implicated for a long time in the pathogenesis of PD.

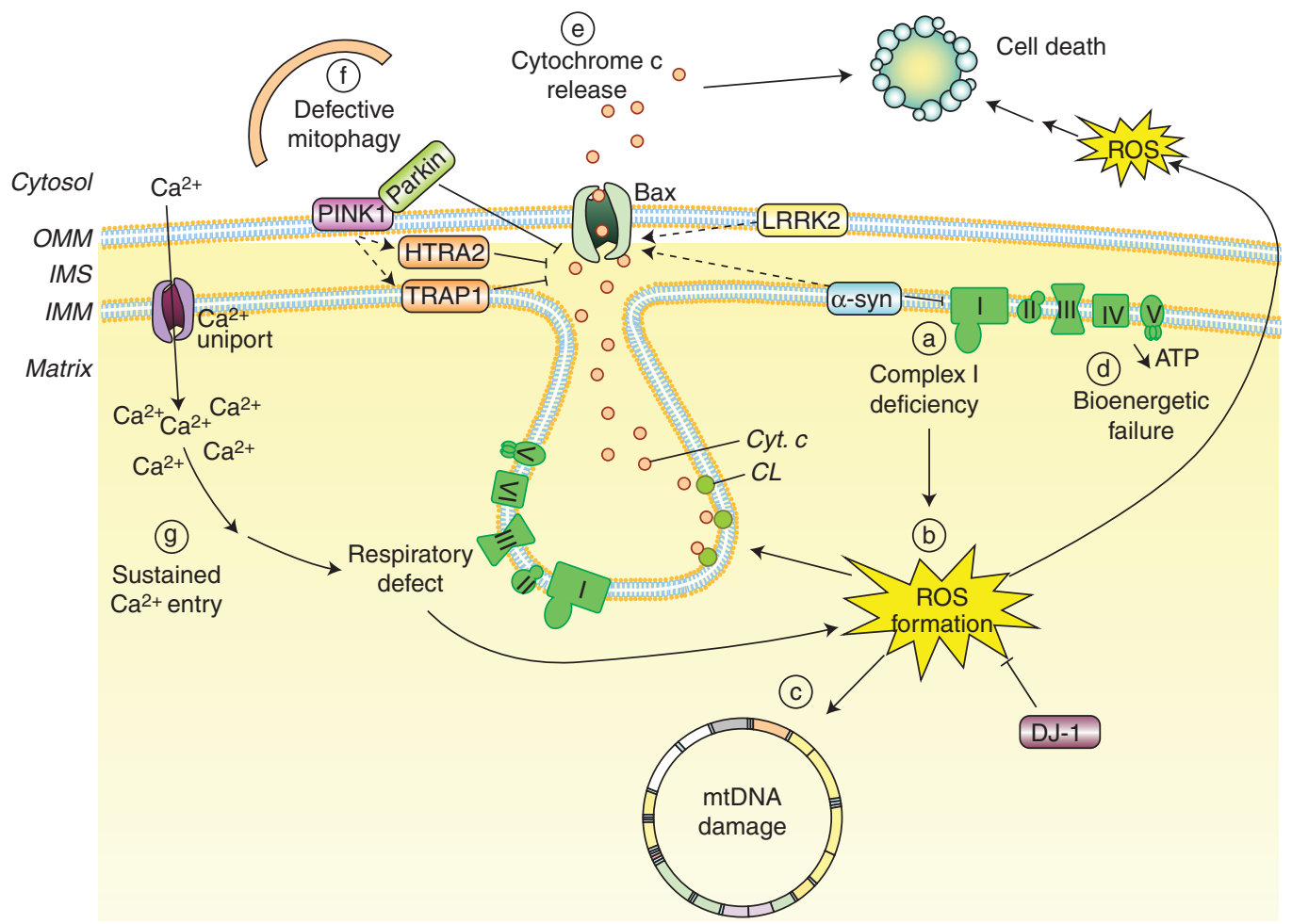

Figure 5. Mitochondrial dysfunction in PD. Alterations in several aspects of mitochondria biology have been linked to the pathogenesis of PD, such as: (a) reduced complex I activity, $(b)$ increased production of mitochondria-derived ROS, $(c)$ ROS-mediated mtDNA damage, $(d)$ bioenergetic failure, $(e)$ Bax-mediated cytochrome $c$ release and activation of mitochondria-dependent apoptotic pathways, $(f)$ defective mitophagy, or $(g)$ increased mitochondrial $\mathrm{Ca}^{2+}$-buffering burden. Many of the mutated nuclear genes linked to familial forms of PD, including PINK1, Parkin, $\alpha$-synuclein, DJ-1, or LRRK2, have been shown to affect many of these mitochondrial features (see main text for details). CL, cardiolipin; Cyt. c, cytochrome $c$; HTRA2, high temperature requirement A2; IMM, inner mitochondrial membrane; IMS, intermembrane space; LRRK2, leucine-rich-repeat kinase 2; OMM, outer mitochondrial membrane PINK1, phosphatase, and tensin homolog-induced kinase 1; ROS, reactive oxygen species; TRAP1, tumor necrosis factor receptor-associated protein $1 ; \alpha$-syn, alpha-synuclein. 
However, the role of mitochondria in PD seems to extend well beyond a sole deficit in respiration (Fig. 5). Although it remains to be shown whether mitochondrial alterations in PD constitute a primary or a secondary event, or are just part of a larger multifactorial pathogenic process, the targeting of mitochondrial dysfunction holds promise for the development of novel therapeutic strategies aimed at halting or slowing down the progression of dopaminergic neurodegeneration in this currently incurable neurodegenerative disorder.

\section{ACKNOWLEDGMENTS}

This work was supported by European Commission Marie Curie Excellence Grant (M.V.), European Commission Marie Curie International Reintegration Grant (M.V.), Fundació la Caixa, Spain (M.V.), FIS-ISCIII, Spain (M.V. and C.P.), MICINN, Spain (M.V.), and Ramón y Cajal Program from MICINN (C.P.).

\section{REFERENCES}

Andres-Mateos E, Perier C, Zhang L, Blanchard-Fillion B, Greco TM, Thomas B, Ko HS, Sasaki M, Ischiropoulos H, Przedborski S, et al. 2007. DJ-1 gene deletion reveals that DJ-1 is an atypical peroxiredoxin-like peroxidase. Proc Natl Acad Sci 104: 14807-14812.

Anisimov VN, Zabezhinski MA, Popovich IG, Piskunova TS, Semenchenko AV, Tyndyk ML, Yurova MN, Antoch MP, Blagosklonny MV. 2010. Rapamycin extends maximal lifespan in cancer-prone mice. Am J Pathol 176: 2092-2097.

Barsoum MJ, Yuan H, Gerencser AA, Liot G, Kushnareva Y, Graber S, Kovacs I, Lee WD, Waggoner J, Cui J, et al. 2006. Nitric oxide-induced mitochondrial fission is regulated by dynamin-related GTPases in neurons. EMBO J 25: 3900-3911.

Bender A, Krishnan KJ, Morris CM, Taylor GA, Reeve AK, Perry RH, Jaros E, Hersheson JS, Betts J, Klopstock T, et al. 2006. High levels of mitochondrial DNA deletions in substantia nigra neurons in aging and Parkinson disease. Nat Genet 38: 515-517.

Betarbet R, Sherer TB, MacKenzie G, Garcia-Osuna M, Panov AV, Greenamyre JT. 2000. Chronic systemic pesticide exposure reproduces features of Parkinson's disease. Nat Neurosci 3: 1301-1306.

Bonifati V, Rizzu P, Van Baren MJ, Schaap O, Breedveld GJ, Krieger E, Dekker MC, Squitieri F, Ibanez P, Joosse M, et al. 2003. Mutations in the DJ-1 gene associated with autosomal recessive early-onset parkinsonism. Science 299: $256-259$.
Bové J, Martinez-Vicente M, Vila M. 2011. Fighting neurodegeneration with rapamycin: Mechanistic insights. Nat Rev Neurosci 12: 437-452.

Braak H, Ghebremedhin E, Rub U, Bratzke H, Del Tredici K. 2004. Stages in the development of Parkinson's diseaserelated pathology. Cell Tissue Res 318: 121-134.

Brown MR, Sullivan PG, Geddes JW. 2006. Synaptic mitochondria are more susceptible to $\mathrm{Ca}^{2+}$ overload than nonsynaptic mitochondria. J Biol Chem 281: 11658-11668.

Chan P, DeLanney LE, Irwin I, Langston JW, Di Monte D. 1991. Rapid ATP loss caused by 1-methyl-4-phenyl$1,2,3,6$ - tetrahydropyridine in mouse brain. J Neurochem 57: $348-351$.

Chan CS, Guzman JN, Ilijic E, Mercer JN, Rick C, Tkatch T, Meredith GE, Surmeier DJ. 2007. "Rejuvenation" protects neurons in mouse models of Parkinson's disease. Nature 447: 1081-1086.

Chan CS, Gertler TS, Surmeier DJ. 2010. A molecular basis for the increased vulnerability of substantia nigra dopamine neurons in aging and Parkinson's disease. Mov Disord 25 (Suppl 1): S63-S70.

Chen H, Chan DC. 2009. Mitochondrial dynamics—fusion, fission, movement, and mitophagy — in neurodegenerative diseases. Hum Mol Genet 18: R169-R176.

Chen H, McCaffery JM, Chan DC. 2007. Mitochondrial fusion protects against neurodegeneration in the cerebellum. Cell 130: 548-562.

Cheng HC, Ulane CM, Burke RE. 2010. Clinical progression in Parkinson disease and the neurobiology of axons. Ann Neurol 67: 715-725.

Chu Y, Dodiya H, Aebischer P, Olanow CW, Kordower JH. 2009. Alterations in lysosomal and proteasomal markers in Parkinson's disease: Relationship to alpha-synuclein inclusions. Neurobiol Dis 35: 385-398.

Crocker SJ, Smith PD, Jackson-Lewis V, Lamba WR, Hayley SP, Grimm E, Callaghan SM, Slack RS, Melloni E, Przedborski S, et al. 2003. Inhibition of calpains prevents neuronal and behavioral deficits in an MPTP mouse model of Parkinson's disease. J Neurosci 23: 4081-4091.

Csordas G, Renken C, Varnai P, Walter L, Weaver D, Buttle KF, Balla T, Mannella CA, Hajnoczky G. 2006. Structural and functional features and significance of the physical linkage between ER and mitochondria. J Cell Biol 174: 915-921.

Cui M, Tang X, Christian WV, Yoon Y, Tieu K. 2010. Perturbations in mitochondrial dynamics induced by human mutant PINK1 can be rescued by the mitochondrial division inhibitor mdivi-1. J Biol Chem 285: 11740-11752.

Damier P, Hirsch EC, Agid Y, Graybiel AM. 1999. The substantia nigra of the human brain. II. Patterns of loss of dopamine-containing neurons in Parkinson's disease. Brain 122: 1437-1448.

Danzer KM, Haasen D, Karow AR, Moussaud S, Habeck M, Giese A, Kretzschmar H, Hengerer B, Kostka M. 2007. Different species of alpha-synuclein oligomers induce calcium influx and seeding. J Neurosci 27: 9220-9232.

Darios F, Corti O, Lucking CB, Hampe C, Muriel MP, Abbas N, Gu WJ, Hirsch EC, Rooney T, Ruberg M, Brice A. 2003. Parkin prevents mitochondrial swelling and cytochrome 
C. Perier and M. Vila

c release in mitochondria-dependent cell death. Hum Mol Genet 12: 517-526.

Dauer W, Przedborski S. 2003. Parkinson's disease: Mechanisms and models. Neuron 39: 889-909.

Davey GP, Clark JB. 1996. Threshold effects and control of oxidative phosphorylation in nonsynaptic rat brain mitochondria. J Neurochem 66: 1617-1624.

Davey GP, Peuchen S, Clark JB. 1998. Energy thresholds in brain mitochondria. Potential involvement in neurodegeneration. J Biol Chem 273: 12753-12757.

Davidzon G, Greene P, Mancuso M, Klos KJ, Ahlskog JE, Hirano M, DiMauro S. 2006. Early-onset familial parkinsonism due to POLG mutations. Ann Neurol 59: 859-862.

de Brito OM, Scorrano L. 2008. Mitofusin 2 tethers endoplasmic reticulum to mitochondria. Nature 456: 605610.

De Stefani D, Raffaello A, Teardo E, Szabo I, Rizzuto R. 2011. A forty-kilodalton protein of the inner membrane is the mitochondrial calcium uniporter. Nature 476: 336-340.

Dehay B, Bové J, Rodriguez-Muela N, Perier C, Recasens A, Boya P, Vila M. 2010. Pathogenic lysosomal depletion in Parkinson's disease. J Neurosci 30: 12535-12544.

Delettre C, Lenaers G, Griffoin JM, Gigarel N, Lorenzo C, Belenguer P, Pelloquin L, Grosgeorge J, Turc-Carel C, Perret E, Astarie-Dequeker C, Lasquellec L, Arnaud B, Ducommun B, Kaplan J, Hamel CP. 2000. Nuclear gene OPA1, encoding a mitochondrial dynamin-related protein, is mutated in dominant optic atrophy. Nat Genet 26: $207-210$.

Detmer SA, Chan DC. 2007. Functions and dysfunctions of mitochondrial dynamics. Nat Rev Mol Cell Biol 8: 870-879.

Di Monte D, Jewell SA, Ekstrom G, Sandy MS, Smith MT. 1986. 1-Methyl-4-phenyl-1,2,3,6-tetrahydropyridine (MPTP) and 1-methyl-4-phenylpyridinium $\left(\mathrm{MPP}^{+}\right)$ cause rapid ATP depletion in isolated hepatocytes. Biochem Biophys Res Commun 137: 310-315.

DiMauro S, Schon EA. 2003. Mechanisms of disease: Mitochondrial respiratory-chain diseases. N Engl J Med 348: 2656-2668.

Ekstrand MI, Terzioglu M, Galter D, Zhu S, Hofstetter C, Lindqvist E, Thams S, Bergstrand A, Hansson FS, Trifunovic A, et al. 2007. Progressive parkinsonism in mice with respiratory-chain-deficient dopamine neurons. Proc Natl Acad Sci 104: 1325-1330.

Frank S, Gaume B, Bergmann-Leitner ES, Leitner WW, Robert EG, Catez F, Smith CL, Youle RJ. 2001. The role of dynamin-related protein 1 , a mediator of mitochondrial fission, in apoptosis. Dev Cell 1: 515-525.

Frei B, Richter C. 1986. N-methyl-4-phenylpyridine $(\mathrm{MMP}+)$ together with 6-hydroxydopamine or dopamine stimulates $\mathrm{Ca}^{2+}$ release from mitochondria. FEBS Lett 198: 99-102.

Frezza C, Cipolat S, Martins de Brito O, Micaroni M, Beznoussenko GV, Rudka T, Bartoli D, Polishuck RS, Danial NN, De Strooper B, et al. 2006. OPA1 controls apoptotic cristae remodeling independently from mitochondrial fusion. Cell 126: 177-189.
Galluzzi L, Blomgren K, Kroemer G. 2009. Mitochondrial membrane permeabilization in neuronal injury. Nat Rev Neurosci 10: 481-494.

Gandhi S, Wood-Kaczmar A, Yao Z, Plun-Favreau H, Deas E, Klupsch K, Downward J, Latchman DS, Tabrizi SJ, Wood NW, Duchen MR, Abramov AY. 2009. PINK1-associated Parkinson's disease is caused by neuronal vulnerability to calcium-induced cell death. Mol Cell 33: 627-638.

Geisler S, Holmstrom KM, Skujat D, Fiesel FC, Rothfuss OC, Kahle PJ, Springer W. 2010. PINK1/Parkinmediated mitophagy is dependent on VDAC1 and p62/ SQSTM1. Nat Cell Biol 12: 119-131.

German DC, Manaye KF, Sonsalla PK, Brooks BA. 1992. Midbrain dopaminergic cell loss in Parkinson's disease and MPTP-induced parkinsonism: Sparing of calbindin-D28k-containing cells. Ann NY Acad Sci 648: 42-62.

Gleichmann M, Mattson MP. 2011. Neuronal calcium homeostasis and dysregulation. Antioxid Redox Signal 14: 1261-1273.

Gomez-Lazaro M, Bonekamp NA, Galindo MF, Jordan J, Schrader M. 2008. 6-Hydroxydopamine (6-OHDA) induces Drp1-dependent mitochondrial fragmentation in SH-SY5Y cells. Free Radic Biol Med 44: 1960-1969.

Gu M, Cooper JM, Taanman JW, Schapira AH. 1998. Mitochondrial DNA transmission of the mitochondrial defect in Parkinson's disease. Ann Neurol 44: 177-186.

Guarente L. 2008. Mitochondria-a nexus for aging, calorie restriction, and sirtuins? Cell 132: 171-176.

Guzman JN, Sanchez-Padilla J, Wokosin D, Kondapalli J, Ilijic E, Schumacker PT, Surmeier DJ. 2010. Oxidant stress evoked by pacemaking in dopaminergic neurons is attenuated by DJ-1. Nature 468: 696-700.

Harrison DE, Strong R, Sharp ZD, Nelson JF, Astle CM, Flurkey K, Nadon NL, Wilkinson JE, Frenkel K, Carter CS, et al. 2009. Rapamycin fed late in life extends lifespan in genetically heterogeneous mice. Nature 460: 392-395.

Hoang T, Choi DK, Nagai M, Wu DC, Nagata T, Prou D, Wilson GL, Vila M, Jackson-Lewis V, Dawson VL, et al. 2009. Neuronal NOS and cyclooxygenase- 2 contribute to DNA damage in a mouse model of Parkinson disease. Free Radic Biol Med 47: 1049-1056.

Hollenbeck PJ. 1996. The pattern and mechanism of mitochondrial transport in axons. Front Biosci 1: d91-d102.

Iaccarino C, Crosio C, Vitale C, Sanna G, Carri MT, Barone P. 2007. Apoptotic mechanisms in mutant LRRK2-mediated cell death. Hum Mol Genet 16: 1319-1326.

Irrcher I, Aleyasin H, Seifert EL, Hewitt SJ, Chhabra S, Phillips M, Lutz AK, Rousseaux MW, Bevilacqua L, Jahani-Asl A, et al. 2010. Loss of the Parkinson's diseaselinked gene DJ-1 perturbs mitochondrial dynamics. Hum Mol Genet 19: 3734-3746.

Jung C, Chylinski TM, Pimenta A, Ortiz D, Shea TB. 2004. Neurofilament transport is dependent on actin and myosin. J Neurosci 24: 9486-9496.

Kamp F, Exner N, Lutz AK, Wender N, Hegermann J, Brunner B, Nuscher B, Bartels T, Giese A, Beyer K, et al. 2010 Inhibition of mitochondrial fusion by alpha-synuclein is rescued by PINK1, Parkin and DJ-1. EMBO J 29: 3571-3589. 
Keating DJ. 2008. Mitochondrial dysfunction, oxidative stress, regulation of exocytosis and their relevance to neurodegenerative diseases. J Neurochem 104: 298-305.

Keeney PM, Xie J, Capaldi RA, Bennett JP Jr. 2006. Parkinson's disease brain mitochondrial complex I has oxidatively damaged subunits and is functionally impaired and misassembled. J Neurosci 26: 5256-5264.

Kiebish MA, Han X, Cheng H, Lunceford A, Clarke CF Moon H, Chuang JH, Seyfried TN. 2008. Lipidomic analysis and electron transport chain activities in C57BL/6J mouse brain mitochondria. J Neurochem 106: 299-312.

Kim I, Rodriguez-Enriquez S, Lemasters JJ. 2007. Selective degradation of mitochondria by mitophagy. Arch Biochem Biophys 462: 245-253.

Kim-Han JS, Antenor-Dorsey JA, O'Malley KL. 2011. The Parkinsonian mimetic, $\mathrm{MPP}^{+}$, specifically impairs mitochondrial transport in dopamine axons. J Neurosci 31: $7212-7221$.

Knott AB, Perkins G, Schwarzenbacher R, Bossy-Wetzel E. 2008. Mitochondrial fragmentation in neurodegeneration. Nat Rev Neurosci 9: 505-518.

Kraytsberg Y, Kudryavtseva E, McKee AC, Geula C, Kowall NW, Khrapko K. 2006. Mitochondrial DNA deletions are abundant and cause functional impairment in aged human substantia nigra neurons. Nat Genet 38: 518-520.

Kujoth GC, Hiona A, Pugh TD, Someya S, Panzer K, Wohlgemuth SE, Hofer T, Seo AY, Sullivan R, Jobling WA, et al. 2005. Mitochondrial DNA mutations, oxidative stress, and apoptosis in mammalian aging. Science 309: 481484.

Langston JW, Ballard P, Irwin I. 1983. Chronic parkinsonism in humans due to a product of meperidine-analog synthesis. Science 219: 979-980.

Larsson NG. 2010. Somatic mitochondrial DNA mutations in mammalian aging. Annu Rev Biochem 79: 683-706.

Liang LP, Patel M. 2004. Iron-sulfur enzyme mediated mitochondrial superoxide toxicity in experimental Parkinson's disease. J Neurochem 90: 1076-1084.

Liang CL, Wang TT, Luby-Phelps K, German DC. 2007. Mitochondria mass is low in mouse substantia nigra dopamine neurons: Implications for Parkinson's disease. Exp Neurol 203: 370-380.

Luoma P, Melberg A, Rinne JO, Kaukonen JA, Nupponen NN, Chalmers RM, Oldfors A, Rautakorpi I, Peltonen L, Majamaa K, et al. 2004. Parkinsonism, premature menopause, and mitochondrial DNA polymerase gamma mutations: Clinical and molecular genetic study. Lancet 364: 875-882.

Lutz AK, Exner N, Fett ME, Schlehe JS, Kloos K, Lammermann K, Brunner B, Kurz-Drexler A, Vogel F, Reichert AS, et al. 2009. Loss of parkin or PINK1 function increases Drp1-dependent mitochondrial fragmentation. J Biol Chem 284: 22938-22951.

Marella M, Seo BB, Nakamaru-Ogiso E, Greenamyre JT, Matsuno-Yagi A, Yagi T. 2008. Protection by the NDI1 gene against neurodegeneration in a rotenone rat model of Parkinson's disease. PLoS ONE 3: e1433.

Martinez-Vicente M, Talloczy Z, Kaushik S, Massey AC, Mazzulli J, Mosharov EV, Hodara R, Fredenburg R, Wu DC, Follenzi A, Dauer W, et al. 2008. Dopamine- modified alpha-synuclein blocks chaperone-mediated autophagy. J Clin Invest 118: 777-788.

Meuer K, Suppanz IE, Lingor P, Planchamp V, Goricke B, Fichtner L, Braus GH, Dietz GP, Jakobs S, Bahr M, et al. 2007. Cyclin-dependent kinase 5 is an upstream regulator of mitochondrial fission during neuronal apoptosis. Cell Death Differ 14: 651-661.

Migliaccio E, Giorgio M, Mele S, Pelicci G, Reboldi P, Pandolfi PP, Lanfrancone L, Pelicci PG. 1999. The p66shc adaptor protein controls oxidative stress response and life span in mammals. Nature 402: 309-313.

Mochizuki H, Hayakawa H, Migita M, Shibata M, Tanaka R, Suzuki A, Shimo-Nakanishi Y, Urabe T, Yamada M, Tamayose K, et al. 2001. An AAV-derived Apaf-1 dominant negative inhibitor prevents MPTP toxicity as antiapoptotic gene therapy for Parkinson's disease. Proc Natl Acad Sci 98: 10918-10923.

Morfini G, Pigino G, Opalach K, Serulle Y, Moreira JE, Sugimori M, Llinas RR, Brady ST. 2007. 1-Methyl-4-phenylpyridinium affects fast axonal transport by activation of caspase and protein kinase C. Proc Natl Acad Sci 104: 2442-2447.

Nakamura K, Nemani VM, Azarbal F, Skibinski G, Levy JM, Egami K, Munishkina L, Zhang J, Gardner B, Wakabayashi J, et al. 2011. Direct membrane association drives mitochondrial fission by the Parkinson disease-associated protein $\alpha$-synuclein. J Biol Chem 286: 20710-20726.

Narendra DP, Jin SM, Tanaka A, Suen DF, Gautier CA, Shen J, Cookson MR, Youle RJ. 2010. PINK1 is selectively stabilized on impaired mitochondria to activate Parkin. PLoS Biol 8: e1000298.

Offen D, Beart PM, Cheung NS, Pascoe CJ, Hochman A, Gorodin S, Melamed E, Bernard R, Bernard O. 1998. Transgenic mice expressing human $\mathrm{Bcl}-2$ in their neurons are resistant to 6-hydroxydopamine and 1-methyl4-phenyl-1,2,3,6-tetrahydropyridine neurotoxicity. Proc Natl Acad Sci 95: 5789-5794.

Okawara M, Katsuki H, Kurimoto E, Shibata H, Kume T, Akaike A. 2007. Resveratrol protects dopaminergic neurons in midbrain slice culture from multiple insults. Biochem Pharmacol 73: 550-560.

Parihar MS, Parihar A, Fujita M, Hashimoto M, Ghafourifar P. 2008. Mitochondrial association of alpha-synuclein causes oxidative stress. Cell Mol Life Sci 65: 1272-1284.

Parker WD Jr, Boyson SJ, Parks JK. 1989. Abnormalities of the electron transport chain in idiopathic Parkinson's disease. Ann Neurol 26: 719-723.

Perier C, Tieu K, Guegan C, Caspersen C, Jackson-Lewis V, Carelli V, Martinuzzi A, Hirano M, Przedborski S, Vila M. 2005. Complex I deficiency primes Bax-dependent neuronal apoptosis through mitochondrial oxidative damage. Proc Natl Acad Sci 102: 19126-19131.

Perier C, Bové J, Wu DC, Dehay B, Choi DK, Jackson-Lewis V, Rathke-Hartlieb S, Bouillet P, Strasser A, Schulz JB, et al. 2007. Two molecular pathways initiate mitochondria-dependent dopaminergic neurodegeneration in experimental Parkinson's disease. Proc Natl Acad Sci 104: $8161-8166$.

Perier C, Bové J, Dehay B, Jackson-Lewis V, Rabinovitch PS, Przedborski S, Vila M. 2010. Apoptosis-inducing factor deficiency sensitizes dopaminergic neurons to parkinsonian neurotoxins. Ann Neurol 68: 184-192. 


\section{Perier and M. Vila}

Perier C, Bové J, Vila M. 2011. Mitochondria and programmed cell death in Parkinson's disease: Apoptosis and beyond. Antioxid Redox Signal doi: 10.1089/ars. 2011.4074

Petit A, Kawarai T, Paitel E, Sanjo N, Maj M, Scheid M, Chen F, Gu Y, Hasegawa H, Salehi-Rad S, et al. 2005. Wild-type PINK1 prevents basal and induced neuronal apoptosis, a protective effect abrogated by Parkinson disease-related mutations. J Biol Chem 280: 34025-34032.

Pinton P, Rimessi A, Marchi S, Orsini F, Migliaccio E, Giorgio M, Contursi C, Minucci S, Mantovani F, Wieckowski MR, et al. 2007. Protein kinase $C$ beta and prolyl isomerase 1 regulate mitochondrial effects of the life-span determinant pp66Shc. Science 315: 659-663.

Ramsay RR, Kowal AT, Johnson MK, Salach JI, Singer TP. 1987. The inhibition site of $\mathrm{MPP}^{+}$, the neurotoxic bioactivation product of 1-methyl-4-phenyl-1,2,3,6-tetrahydropyridine is near the Q-binding site of $\mathrm{NADH}$ dehydrogenase. Arch Biochem Biophys 259: 645-649.

Richardson JR, Shalat SL, Buckley B, Winnik B, O'Suilleabhain P, Diaz-Arrastia R, Reisch J, German DC. 2009. Elevated serum pesticide levels and risk of Parkinson disease. Arch Neurol 66: 870-875.

Schapira AH, Cooper JM, Dexter D, Clark JB, Jenner P, Marsden CD. 1990. Mitochondrial complex I deficiency in Parkinson's disease. J Neurochem 54: 823-827.

Schon EA, Przedborski S. 2011. Mitochondria: The next (neurode)generation. Neuron 70: 1033-1053.

Schriner SE, Linford NJ, Martin GM, Treuting P, Ogburn CE, Emond M, Coskun PE, Ladiges W, Wolf N, Van Remmen H, et al. 2005. Extension of murine life span by overexpression of catalase targeted to mitochondria. Science 308: 1909-1911.

Schuh RA, Kristian T, Gupta RK, Flaws JA, Fiskum G. 2005. Methoxychlor inhibits brain mitochondrial respiration and increases hydrogen peroxide production and CREB phosphorylation. Toxicol Sci 88: 495-504.

Schuh RA, Richardson JR, Gupta RK, Flaws JA, Fiskum G. 2009. Effects of the organochlorine pesticide methoxychlor on dopamine metabolites and transporters in the mouse brain. Neurotoxicology 30: 274-280.

Scorrano L, Ashiya M, Buttle K, Weiler S, Oakes SA, Mannella CA, Korsmeyer SJ. 2002. A distinct pathway remodels mitochondrial cristae and mobilizes cytochrome c during apoptosis. Developmental Cell 2: 55-67.

Scotcher KP, Irwin I, DeLanney LE, Langston JW, Di Monte D. 1990. Effects of 1-methyl-4-phenyl-1,2,3,6-tetrahydropyridine and 1-methyl-4-phenylpyridinium ion on ATP levels of mouse brain synaptosomes. J Neurochem 54: 1295-1301.

Sheehan JP, Swerdlow RH, Parker WD, Miller SW, Davis RE, Tuttle JB. 1997. Altered calcium homeostasis in cells transformed by mitochondria from individuals with Parkinson's disease. J Neurochem 68: 1221-1233.

Sherer TB, Betarbet R, Greenamyre JT. 2002. Environment, mitochondria, and Parkinson's disease. Neuroscientist 8: 192-197.

Shin JH, Ko HS, Kang H, Lee Y, Lee YI, Pletinkova O, Troconso JC, Dawson VL, Dawson TM. 2011. PARIS (ZNF746) repression of PGC-1alpha contributes to neurodegeneration in Parkinson's disease. Cell 144: 689-702.
Sousa SC, Maciel EN, Vercesi AE, Castilho RF. 2003. $\mathrm{Ca}^{2+}$. induced oxidative stress in brain mitochondria treated with the respiratory chain inhibitor rotenone. FEBS Lett 543: 179-183.

St Pierre J, Drori S, Uldry M, Silvaggi JM, Rhee J, Jager S, Handschin C, Zheng K, Lin J, Yang W, et al. 2006. Suppression of reactive oxygen species and neurodegeneration by the PGC-1 transcriptional coactivators. Cell 127: 397-408.

Swerdlow RH, Parks JK, Miller SW, Tuttle JB, Trimmer PA, Sheehan JP, Bennett JP Jr, Davis RE, Parker WD Jr. 1996. Origin and functional consequences of the complex I defect in Parkinson's disease. Ann Neurol 40: 663-671.

Szabadkai G, Simoni AM, Bianchi K, De Stefani D, Leo S, Wieckowski MR, Rizzuto R. 2006. Mitochondrial dynamics and $\mathrm{Ca}^{2+}$ signaling. Biochim Biophys Acta 1763: 442-449.

Tait SW, Green DR. 2010. Mitochondria and cell death: Outer membrane permeabilization and beyond. Nat Rev Mol Cell Biol 11: 621-632.

Thyagarajan D, Bressman S, Bruno C, Przedborski S, Shanske S, Lynch T, Fahn S, DiMauro S. 2000. A novel mitochondrial 12SrRNA point mutation in parkinsonism, deafness, and neuropathy. Ann Neurol 48: 730-736.

Tieu K, Perier C, Caspersen C, Teismann P, Wu DC, Yan SD, Naini A, Vila M, Jackson-Lewis V, Ramasamy R. 2003. Dbeta-hydroxybutyrate rescues mitochondrial respiration and mitigates features of Parkinson disease. J Clin Invest 112: $892-901$.

Trifunovic A, Wredenberg A, Falkenberg M, Spelbrink JN, Rovio AT, Bruder CE, Bohlooly Y, Gidlof S, Oldfors A, Wibom R, et al. 2004. Premature ageing in mice expressing defective mitochondrial DNA polymerase. Nature 429: 417-423.

Trimmer PA, Borland MK, Keeney PM, Bennett JP Jr, Parker WD Jr. 2004. Parkinson's disease transgenic mitochondrial cybrids generate Lewy inclusion bodies. J Neurochem 88: 800-812.

Vermulst M, Bielas JH, Kujoth GC, Ladiges WC, Rabinovitch PS, Prolla TA, Loeb LA. 2007. Mitochondrial point mutations do not limit the natural lifespan of mice. Nat Genet 39: 540-543.

Vermulst M, Wanagat J, Kujoth GC, Bielas JH, Rabinovitch PS, Prolla TA, Loeb LA. 2008. DNA deletions and clonal mutations drive premature aging in mitochondrial mutator mice. Nat Genet 40: 392-394.

Verstreken P, Ly CV, Venken KJ, Koh TW, Zhou Y, Bellen HJ. 2005. Synaptic mitochondria are critical for mobilization of reserve pool vesicles at Drosophila neuromuscular junctions. Neuron 47: 365-378.

Vila M, Przedborski S. 2003. Targeting programmed cell death in neurodegenerative diseases. Nat Rev Neurosci 4: 365-375.

Vila M, Przedborski S. 2004. Genetic clues to the pathogenesis of Parkinson's disease. Nat Med 10 (Suppl 1): S58-S62.

Vila M, Jackson-Lewis V, Vukosavic S, Djaldetti R, Liberatore G, Offen D, Korsmeyer SJ, Przedborski S. 2001. Bax ablation prevents dopaminergic neurodegeneration in the 1-methyl-4-phenyl-1,2,3,6-tetrahydropyridine mouse model of Parkinson's disease. Proc Natl Acad Sci 98: $2837-2842$. 
Vila M, Ramonet D, Perier C. 2008. Mitochondrial alterations in Parkinson's disease: New clues.J Neurochem 107: $317-328$.

Vila M, Bové J, Dehay B, Rodriguez-Muela N, Boya P. 2011 Lysosomal membrane permeabilization in Parkinson disease. Autophagy 7: 98-100.

Viswanath V, Wu Y, Boonplueang R, Chen S, Stevenson FF Yantiri F, Yang L, Beal MF, Andersen JK. 2001. Caspase-9 activation results in downstream caspase- 8 activation and bid cleavage in 1-methyl-4-phenyl-1,2,3,6-tetrahydropyridine-induced Parkinson's disease. J Neurosci 21: 9519-9528.

Vives-Bauza C, Tocilescu M, Devries RL, Alessi DM, Jackson-Lewis V, Przedborski S. 2010a. Control of mitochondrial integrity in Parkinson's disease. Prog Brain Res 183: 99-113.

Vives-Bauza C, Zhou C, Huang Y, Cui M, de Vries RL, Kim J, May J, Tocilescu MA, Liu W, Ko HS, et al. 2010b. PINK1dependent recruitment of Parkin to mitochondria in mitophagy. Proc Natl Acad Sci 107: 378-383.

Wallace DC. 2005. A mitochondrial paradigm of metabolic and degenerative diseases, aging, and cancer: A dawn for evolutionary medicine. Annu Rev Genet 39: 359-407.

Wang XJ, Xu JX. 2005. Possible involvement of $\mathrm{Ca}^{2+}$ signaling in rotenone-induced apoptosis in human neuroblastoma SH-SY5Y cells. Neurosci Lett 376: 127-132.

Wang HL, Chou AH, Yeh TH, Li AH, Chen YL, Kuo YL, Tsai SR, Yu ST. 2007. PINK1 mutants associated with recessive Parkinson's disease are defective in inhibiting mitochondrial release of cytochrome c. Neurobiol Dis 28: 216-226.
Wen Y, Li W, Poteet EC, Xie L, Tan C, Yan LJ, Ju X, Liu R, Qian H, Marvin MA, et al. 2011. Alternative mitochondrial electron transfer as a novel strategy for neuroprotection. J Biol Chem 286: 16504-16515.

Yamada M, Iwatsubo T, Mizuno Y, Mochizuki H. 2004. Overexpression of alpha-synuclein in rat substantia nigra results in loss of dopaminergic neurons, phosphorylation of alpha-synuclein and activation of caspase-9: Resemblance to pathogenetic changes in Parkinson's disease. J Neurochem 91: 451-461.

Yang LC, Matthews RT, Schulz JB, Klockgether T, Liao AW, Martinou JC, Penney JB Jr, Hyman BT, Beal MF. 1998. 1-methyl-4-phenyl-1,2,3,6-tetrahydropyride neurotoxicity is attenuated in mice overexpressing Bcl-2. J Neurosci 18: 8145-8152.

Youle RJ, Narendra DP. 2011. Mechanisms of mitophagy. Nat Rev Mol Cell Biol 12: 9-14.

Zheng B, Liao Z, Locascio JJ, Lesniak KA, Roderick SS, Watt ML, Eklund AC, Zhang-James Y, Kim PD, Hauser MA, Grunblatt E, et al. 2010. PGC-1alpha, a potential therapeutic target for early intervention in Parkinson's disease. Sci Transl Med 2: 52 ra73.

Zhou C, Huang Y, Przedborski S. 2008. Oxidative stress in Parkinson's disease: A mechanism of pathogenic and therapeutic significance. Ann NYAcad Sci 1147: 93-104.

Zuchner S, Mersiyanova IV, Muglia M, Bissar-Tadmouri N, Rochelle J, Dadali EL, Zappia M, Nelis E, Patitucci A, Senderek J, et al. 2004. Mutations in the mitochondrial GTPase mitofusin 2 cause Charcot-Marie-Tooth neuropathy type 2A. Nat Genet 36: 449-451. 


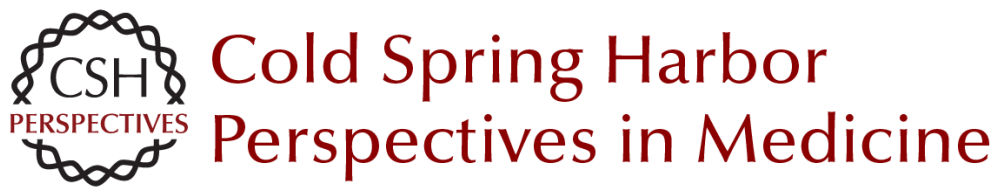

\section{Mitochondrial Biology and Parkinson's Disease}

Celine Perier and Miquel Vila

Cold Spring Harb Perspect Med 2012; doi: 10.1101/cshperspect.a009332 originally published online November 8, 2011

\section{Subject Collection Parkinson's Disease}

Functional Neuroanatomy of the Basal Ganglia José L. Lanciego, Natasha Luquin and José A. Obeso

Animal Models of Parkinson's Disease: Vertebrate Genetics Yunjong Lee, Valina L. Dawson and Ted M. Dawson

Innate Inflammation in Parkinson's Disease V. Hugh Perry

Parkinson's Disease and Parkinsonism:

Neuropathology Dennis W. Dickson

Physiological Phenotype and Vulnerability in Parkinson's Disease

D. James Surmeier, Jaime N. Guzman, Javier Sanchez, et al.

Clinical Approach to Parkinson's Disease:

Features, Diagnosis, and Principles of Management João Massano and Kailash P. Bhatia

The Role of Autophagy in Parkinson's Disease Melinda A. Lynch-Day, Kai Mao, Ke Wang, et al.

Disruption of Protein Quality Control in Parkinson's Disease Casey Cook, Caroline Stetler and Leonard Petrucelli
Drosophila as a Model to Study Mitochondrial Dysfunction in Parkinson's Disease Ming Guo

Parkinsonism Due to Mutations in PINK1, Parkin, and DJ-1 and Oxidative Stress and Mitochondrial Pathways Mark R. Cookson

Programmed Cell Death in Parkinson's Disease Katerina Venderova and David S. Park

Genomics and Bioinformatics of Parkinson's Disease Sonja W. Scholz, Tim Mhyre, Habtom Ressom, et al.

Motor Control Abnormalities in Parkinson's

Disease Pietro Mazzoni, Britne Shabbott and Juan Camilo Cortés

Parkinson's Disease: Gene Therapies Philippe G. Coune, Bernard L. Schneider and Patrick Aebischer

Functional Neuroimaging in Parkinson's Disease Martin Niethammer, Andrew Feigin and David Eidelberg

Leucine-Rich Repeat Kinase 2 for Beginners: Six Key Questions Lauren R. Kett and William T. Dauer

For additional articles in this collection, see http://perspectivesinmedicine.cshlp.org/cgi/collection/ 